\title{
NeuroRegulation
}

\section{Neurocognitive Enhancement: Applications and Ethical Issues}

\author{
Giulia Fronda ${ }^{1,2}$, Davide Crivelli1,2, and Michela Balconi, ${ }^{1,2}$ \\ ${ }^{1}$ Research Unit in Affective and Social Neuroscience, Catholic University of the Sacred Heart, Milan, Italy \\ ${ }^{2}$ Department of Psychology, Catholic University of the Sacred Heart, Milan, Italy
}

\begin{abstract}
In recent years, the interest in neurocognitive empowerment has increased, thus making it a hot topic, especially because of possible ethical implications. Specifically, the term neurocognitive empowerment refers to the use of different neuroscientific techniques and tools that increase the cognitive functioning of the individual beyond the normal threshold-on the one hand, improving functions such as attention, perception, and memory-and, on the other hand, physical and motor functions. Neuroethics is peculiarly interested in monitoring and discussing ethical implications and possible consequences or undesirable effects of neurocognitive strengthening techniques. In particular, the use of different tools for neurocognitive enhancement requires an in-depth analysis of the ethical and legal principles in terms of security and social justice that allow the improvement of mental and physical functions of an individual. The present work aims at introducing the use of specific techniques-such as neurofeedback devices for the enhancement of attention regulation skill-in specific application contexts; that is, sports in which athletes are continuously subjected to external pressures for performance and constant improvement. Furthermore, this document explores possible ethical critical issues raised by such use of neurocognitive enhancement techniques.
\end{abstract}

Keywords: neuroethics; neurocognitive enhancement; peak performance; wearable devices; sports

Citation: Fronda, G., Crivelli, D., \& Balconi, M. (2019). Neurocognitive enhancement: Applications and ethical issues. NeuroRegulation, 6(3) 161-168. https://doi.org/10.15540/nr.6.3.161

*Address correspondence to: Giulia Fronda, Research Unit in Affective and Social Neuroscience, Department of Psychology Catholic University of the Sacred Heart, Largo Gemelli 1, 20123, Milano, Italy. Email: giulia.fronda@unicatt.it

Copyright: (c) 2019. Fronda et al. This is an Open Access article distributed under the terms of the Creative Commons Attribution License (CC-BY).
Edited by:

Rex L. Cannon, PhD, SPESA Research Institute, Knoxville, Tennessee, USA

Reviewed by:

Rex L. Cannon, PhD, SPESA Research Institute, Knoxville, Tennessee, USA

Nancy L. Wigton, PhD, Grand Canyon University, Phoenix, Arizona, USA

\section{Preliminary Definitions: Why Neurocognitive Enhancement}

Neurocognitive enhancement is a theme of the latest definition. Whilst the term neuroenhancement was, at first, frequently paired with those of doping and brain drugs and with the idea of boosting neural activity to improve cognitive and motor skills (Bell, Partridge, Lucke, \& Hall, 2013; Dodge, Williams, Marzell, \& Turrisi, 2012; Svetlov, Kobeissy, \& Gold, 2007), in recent years the interest into its implications and potential for performance improvement and promotion of optimal functioning in many professional contexts has progressively grown (Bell, Bryson, Greig, Corcoran, \& Wexler, 2001; Fronda, Balconi, \& Crivelli, 2018; Shook \& Giordano, 2016).
Neurocognitive enhancement refers, in particular, to qualitative and/or quantitative improvement of specific cognitive-affective skills or sets of cognitive functions (Farah, 2005; Fronda et al., 2018; Lucke \& Partridge, 2013; Nagel, 2010, 2014), which can be modulated by means of various neuroscientific techniques. Such techniques (e.g., noninvasive brain stimulation and neurofeedback), by acting on brain structures and on neural networks within the central nervous system, allow modulating brain activity during a given task with the final aim of improving information-processing; optimizing the functionality of perceptual, attention, and cognitive systems; and making them operate in a more adaptive, flexible, and efficient way (Bostrom \& Sandberg, 2009; Harvey, 2008). Indeed, 
neuroenhancement interventions usually aim to increase mental functioning beyond what is necessary to sustain or restore a condition of individual well-being (Juengst, 1998). The alteration of brain functions occurs because the brain can change in response to stimulating experiences, practice, or specific training (Engvig et al., 2012; Lövdén, Bäckman, Lindenberger, Schaefer, \& Schmiedek, 2010; Schooler, 1984; Schooler, Mulatu, \& Oates, 1999). Specifically, cognitive enhancement through given training can be aimed at improving a specific function or enhancing the effectiveness of certain activities (Anguera et al., 2013; Chapman et al., 2013; Dahlin, Nyberg, Bäckman, \& Neely, 2008; Jaeggi, Buschkuehl, Jonides, \& Perrig, 2008; Nyberg et al., 2003; Valenzuela-Fernández, Cabrero, Serrador, \& Sánchez-Madrid, 2008; Zelinski \& Reyes, 2010). Therefore, through neurocognitive enhancement, it is possible to optimize the functioning of specific cognitive functions to achieve optimal performance (Agar, 2013).

\section{Neuroscientific Techniques for Sports Performance Enhancement}

The interest in neuroscience focuses specifically on the implementation of different interventions aimed at enhancing performance in various contexts, such as sports. In the sports context, there is a continuous demand for improvement in performance across all levels of expertise, from amateurs to semiprofessional and professional athletes. Advances in neuroscience suggest that sports performance can be enhanced by using methods and techniques that modify brain activity, thus leading to the improvement of athletes' mental state and focus, as well as encouraging motor learning (Vargo et al., 2014). Recently, the potential and effectiveness of noninvasive brain stimulation techniques (i.e., neuroscientific intervention techniques, able to safely induce neuromodulation or neurostimulation effects on cortical structures and networks)-and of combined neurofeedback and mental training programs for pursuing such goals and for optimizing athletes' cognitive and behavioral performances-have been more and more explicitly explored (Balconi, Fronda, Venturella, \& Crivelli, 2017; Balconi, Pala, Crivelli, \& Milone, 2019; Borducchi et al., 2016; Colzato, Nitsche, \& Kibele, 2017; Crivelli, Fronda, Venturella, \& Balconi, 2019; Davis, 2013; Lewthwaite \& Wulf, 2017). While the attention given to potential applications of noninvasive stimulation and neuromodulation techniques likely followed the need for novel models and methods for intervention and the will to try and overcome limitations and ethical issues raised by first tentative neuroenhancement approaches based on chemicals and psychoactive drugs, it has to be acknowledged that such potential and its practicalethical implications in the field of sports practice is still a matter of debate. The growing development of those techniques devised to foster the improvement in sports performance has been, for example, defined as a form of "neurodoping" (Davis, 2013). Several studies (Colzato et al., 2017; Flöel et al., 2011) have demonstrated the effectiveness of brain stimulation and neuromodulation techniques for the enhancement of various cognitive functions even outside the laboratory. In the sports context, in particular, brain stimulation and neural entrainment techniques such as transcranial direct current stimulation (tDCS) and transcranial alternate current stimulation (tACS), which are able to modify cerebral excitability and cortical oscillations by working on specific physiological mechanisms of action (Vernon, 2005), have been used to try and foster optimal neurocognitive efficacy and to improve individual performance (Grosprêtre, Ruffino, \& Lebon, 2016). Some studies have shown the effectiveness of these techniques with regard to athletes' physical skills, namely motor learning and muscular strength, and with regard to their cognitive skills, namely learning ability and attention (Vargo et al., 2014). Moreover, recent studies have shown that the use of tDCS to enhance sports performance is useful in modulating and controlling the autonomic nervous system, allowing the increase in the exercise capacity under challenging conditions (Okano et al., 2013; Williams, Hoffman, \& Clark, 2013). Another study (Vitor-Costa et al., 2015) demonstrated the tDCS effectiveness in improving muscle fatigue, exercise tolerance, and visuomotor coordination, as well as long-term implicit learning processes (Antal et al., 2004; Reis et al., 2009; Zhu et al., 2015).

In addition to neuromodulation techniques, several studies have demonstrated the effectiveness for enhancing sports individual's cognitive and behavioral performance of practices and training programs aimed at fostering self-awareness and self-regulation skills via mental training and neuroscientific techniques (Crews \& Landers, 1993; Haufler, Spalding, Santa Maria, \& Hatfield, 2000; Landers et al., 1991; Salazar et al., 1990). Those neurofeedback techniques seem to be able to improve specific aspects of physical or cognitive individuals performance (Alexeeva, Balios, Muravlyova, Sapina, \& Bazanova, 2012; Zoefel, Huster, \& Herrmann, 2011), such as attention regulation or stress management, by helping practicers to become increasingly aware of their 
automatic physiological reactions to different conditions or, for example, of physiological correlates of specific mindsets and by helping them to strengthen individual strategies to adaptively control such reactions and correlates, thus containing or modulating their occurrence.

Similarly, another tool that proved to be useful as a cognitive enhancement technique with relevant effects in terms of performance improvement is biofeedback, which turned out to be valuable for strengthening control over the bodily arousal levels and for empowering emotional regulation and stress management skills, thus helping, for example, practicers to learn how to contain precompetition anxiety and how to redirect mental resources on their present goals fostering the achievement of optimal performance (Wood, 2006).

\section{Ethical Implications of Performance Enhancement}

Despite the positive evidence in favor of the effectiveness of these neurocognitive enhancement techniques in different contexts, cognitive and behavioral performance improvement appears to be a particularly debated topic for possible implications in terms of safety, morals (understood as the result of a system of collective cultural values), and ethics (understood as a set of personally and socially defined behavior rules that guide individuals' actions; Farah et al., 2004; Nagel, 2015; Ray, 2016; Sandel, 2004; Schelle, Faulmüller, Caviola, \& Hewstone, 2014; Singh \& Kelleher, 2010). Up to now, bioethical debate on neuroenhancement mainly focused on pharmacological, technological, nutritional, and behavioral methods used to enhance individual performance. Specifically, the discipline that investigates the ethical implications of cognitive enhancement techniques and performance is neuroethics. The latter has opened an enduring debate on possible implications and on positive and negative consequences of cognitive enhancement techniques and performance optimization (Farah et al., 2004).

The possible adverse effects of neurocognitive enhancement have been accurately recognized in the loss of interindividual equity and in authenticity of an individual's performance (Butcher, 2003), as well as on possible side effects and unwanted consequences of enhancement techniques and methods (Bostrom \& Sandberg, 2009; Farah, 2005; Farah et al., 2004; Wolpe, 2002). Moreover, the possible negative consequences of neurocognitive enhancement techniques have been evaluated in both individual and social terms (Bostrom \& Sandberg, 2009; Butcher, 2003; Farah, 2005; Wolpe, 2002). Farah and colleagues (2004), for example, have highlighted possible problems associated with neurocognitive enhancement techniques in terms of safety, coercion, distributive justice, personality, and tangible values. Regarding safety, the main concerns are related to the uncertainty of possible future side effects derived by the use of various neurocognitive techniques. Concerning coercion and distributive justice, the authors stressed potential ethical issues associated to the presence of and comparison with empowered individuals within different social contexts, such as the workplace, which might lead to situations in which people could be pressured to undergo neurocognitive enhancement protocols and improve their cognitive abilities. Again, another main concern in this regard resides in the fact that the alteration of the overall cognitive functioning, implemented through the use of enhancement drugs or techniques, could modify some personality aspects that would lead to individuals' homologation and to the occurrence of a significant discrepancy between enhanced and unenhanced individuals (Wolpe, 2002). Additionally, altered cognitive functioning in enhanced subjects could also modify individual aspects of the self, thus creating an alteration of the individuals' identity (Butcher, 2003). Furthermore, at the social level, widespread and uncritical use of neurotechnologies and other neurocognitive enhancement techniques could entail high costs for society and lead to the strengthening or creation of social barriers due to the differential use of these techniques and to different opportunities to access them.

These aspects were also emphasized by Fuchs (2006) who noticed some critical aspects of neurocognitive enhancement techniques - such as safety, change of the human condition, and competition-above all within working and sports contexts. Specifically, in the field of sports science and practice, the ethical and moral implications of performance-enhancement interventions are often not properly taken into consideration because athletes are frequently subjected to competitive pressures (Kayser \& Broers, 2013; Petróczi, 2013) that lead them to disregard the harmful effects and the possible health consequences of using performance enhancers (Curry \& Wagman, 2011; Kayser \& Broers, 2013; Morente-Sánchez \& Zabala, 2013). On the other hand, other recent studies and research have stressed the possible beneficial effects of neurocognitive enhancement techniques and methods by emphasizing the effectiveness of 
neuroscientific techniques in improving and increasing individuals' latent abilities without changing their peculiar and distinctively human characteristics (Cohen Kadosh, Johnson, Dick, Cohen Kadosh, \& Blakemore, 2013). Furthermore, other research (Bostrom \& Roache, 2011; Bostrom \& Sandberg, 2009) has demonstrated the safety and efficacy of external devices for the enhancement of cognitive and behavioral performance compared to the use of psychotropic drugs and brain-computer interface technologies.

\section{The Effects of Using Neuroscientific Techniques to Improve Performance in Sports}

As noted above, several studies have highlighted the effectiveness of neurostimulation and neuromodulation techniques in improving and enhancing sports performance. Likewise, different studies have shown the effectiveness of using techniques based on self-awareness and selfregulation to improve athletes' performance and achieve optimal results (Crews \& Landers, 1993; Hammond, 2007; Haufler et al., 2000; Landers et al., 1991; Salazar et al., 1990). As an example, the mechanisms of action of the neurofeedback technique-which is configured as a technique that allows individuals to learn to self-regulate their cortical activity based on the principle of operating conditioning-ground on the delivery of real-time feedbacks (typically acoustic and/or visual feedback) relative to ongoing modulations of brain functioning. Following, processing, and integrating those feedbacks, the practice can learn to modulate the amplitude, frequency, and coherence of distinct electrophysiological components of his or her brain, by voluntarily activating specific states of cortical excitation (Vernon, 2005). See Figures 1 and 2 for visual depictions of the main apparati of neuroregulation and neuroenhancement.

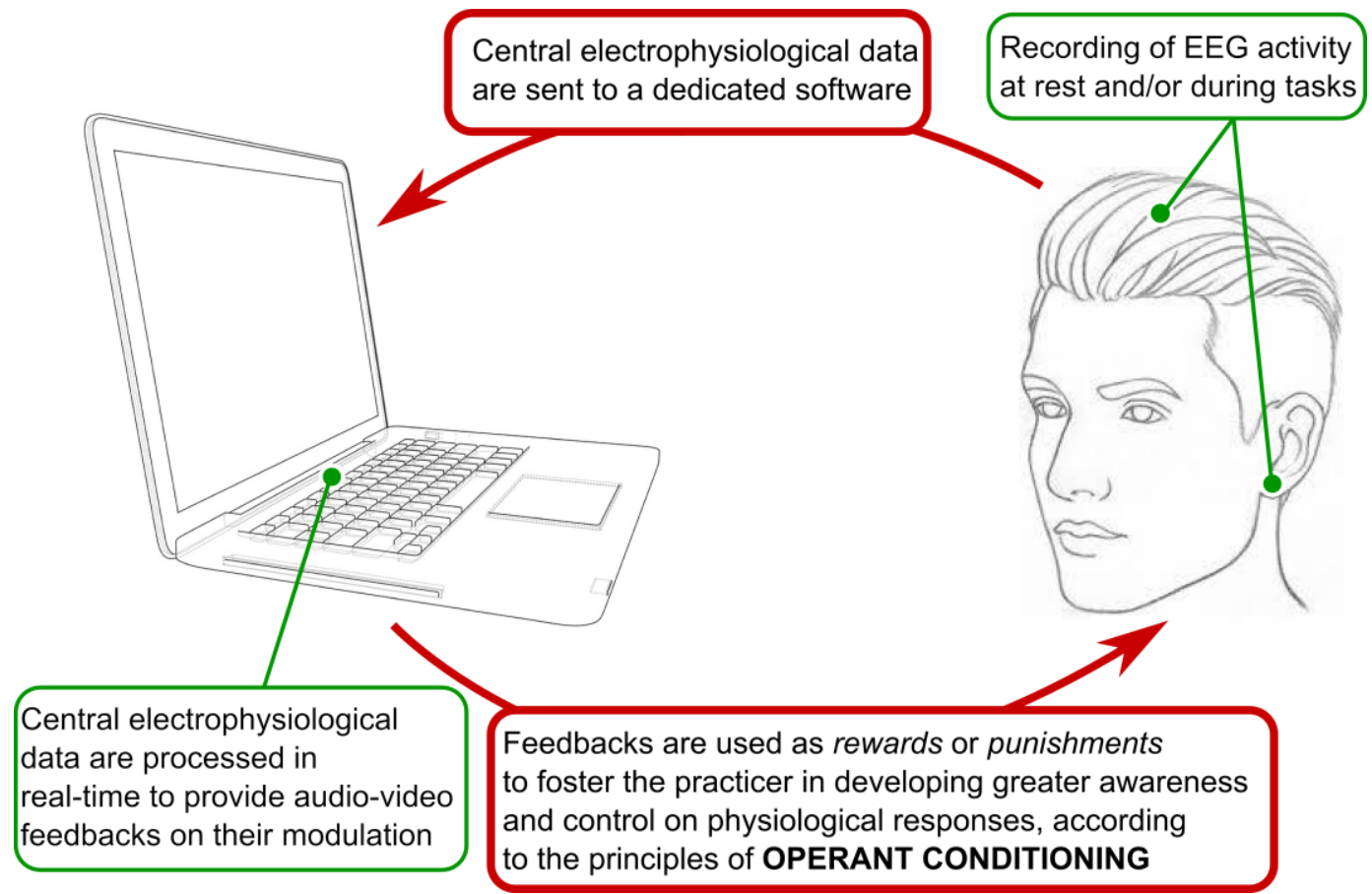

Figure 1. Main steps of the implicit learning cycle promoted by neurofeedback practice. 




Sensors: active electrodes

Practicer: passive stance

Modulation of neural activity: induced by exogenous stimulation

Long-lasting effects due to neuroplastic changes

fostered by external facilitation/inhibition of neural activity that induces cognitive/physical effects
Neurofeedback

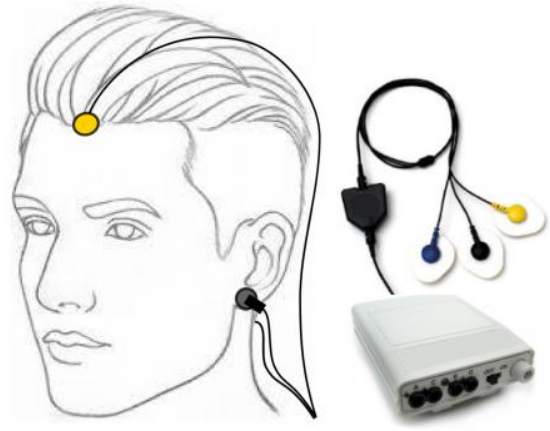

Sensors: passive electrodes Practicer: active stance Modulation of neural activity: induced by endogenous strategies

Long-lasting effects due to neuroplastic changes fostered by implicit learning processes and consolidation of individual self-regulation strategies

Figure 2. Transcranial electrical stimulation and neurofeedback practice: schematic representations of illustrative montages and devices with reference to selected key aspects of the two intervention methods.

It has been shown that the use of neurofeedback in sports allows enhancing athletes' performance through the association between particular patterns of brain activity and behavioral states classified as optimal, improving some principal functions such as the level of concentration, attentive abilities, motivational status, and will (Balconi, Fronda, \& Crivelli, 2018; Hung \& Cheng, 2018).

For example, Balconi et al. (2017) observed the effectiveness of undergoing a mindfulness-based training supported by a wearable neurofeedback device in terms of enhanced cognitive performance, increased concentration, optimized attention regulation, and decreased stress levels in a sample of semiprofessional athletes. Specifically, the efficacy of an intensive 14-day treatment supported by the use of a highly usable and portable neurofeedback device was measured during two assessment phases (T0, T1), during which cognitive, electrophysiological (EEG), autonomic (biofeedback), and neuropsychological outcome measures were collected. Empirical observations added to the limited pieces of evidence suggesting that neurofeedback, through the modulation of electrophysiological central activity (Balconi et al., 2017; Mirifar, Beckmann, \& Ehrlenspiel, 2017), could be an effective method for strengthening attention and emotional regulation, coping with stress, adaptive orientation of mental resources, focusing, and sensorimotor efficiency (Balconi et al., 2018; Crivelli et al., 2019). Again, those observations are also in line with other studies that, in different applied contexts, have observed the effectiveness of different neurofeedback-based training programs as valid enhancement tools able to provide a real-time performance feedback that leads to improved behavioral and physiological markers of neurocognitive efficiency (Balconi et al., 2018; Crivelli et al., 2019; Enriquez-Geppert, Huster, \& Herrmann, 2013; Koberda, Moses, Koberda, \& Koberda, 2012).

\section{Conclusion}

This article provides an overview of the debated topic of neurocognitive enhancement, emphasizing the possible effectiveness and benefits of using neuromodulation and awareness techniques in enhancing sports performance. In this article, a specific focus is also placed on the importance of neuroethics as a discipline that deals with considering the ethical and moral implications of the methods used to achieve optimal performance. The neuroethical debate has mainly focused on the importance of assessing the consequences and possible damage of the use of drugs (Repantis, Schlattmann, Laisney, \& Heuser, 2010; Verhaeghen, Marcoen, \& Goossens, 1992), neurostimulation, and neural entrainment techniques for the enhancement of sports performance (Davis, 2013). Despite the ethical controversies, these latter neuroscientific techniques have shown themselves to be promising in the enhancement of particular essential functions 
for the achievement of optimal results such as the facilitation of different cognitive abilities (Chatterjee, 2004; Sahakian \& Morein-Zamir, 2011), motor learning, muscle strength, and learning skills (Antal et al., 2004; Reis et al., 2009; Vernon, 2005; Zhu et al., 2015).

Further, those benefits are demonstrated by several studies, which have reported no relevant side effects and evidence for better regulation of attention and cognitive control mechanisms following the completion of a combined mindfulnessneurofeedback program within different laboratory and applied contexts (Balconi et al., 2017, 2018, 2019; Crivelli et al., 2019). These results confirm that training self-awareness and self-regulation skills through the use of a wearable neurofeedback device might help athletes, through implicit learning, to improve their ability to focus, to intentionally redirect their attention resources, and to optimize body performance. The effectiveness of these techniques prefigures them as a possible future way to safely improve the mental and physical performance of athletes in different sports contexts.

\section{Author Disclosure}

Authors have no grants, financial interests, or conflicts to disclose.

\section{References}

Agar, N. (2013). Truly human enhancement: A philosophical defense of limits. Cambridge, MA: MIT Press.

Alexeeva, M. V., Balios, N. V., Muravlyova, K. B., Sapina, E. V, \& Bazanova, O. M. (2012). Training for voluntarily increasing individual upper alpha power as a method for cognitive enhancement. Human Physiology, 38(1), 40-48. https://doi.org/10.1134/S0362119711060028

Anguera, J. A., Boccanfuso, J., Rintoul, J. L., Al-Hashimi, O., Faraji, F., Janowich, J., ... Gazzaley, A. (2013). Video game training enhances cognitive control in older adults. Nature, 501(7465), 97-101. https://doi.org/10.1038/nature12486

Antal, A., Nitsche, M. A., Kincses, T. Z., Kruse, W., Hoffmann, K.P., \& Paulus, W. (2004). Facilitation of visuo-motor learning by transcranial direct current stimulation of the motor and extrastriate visual areas in humans. European Journal of Neuroscience, 19(10), 2888-2892. https://doi.org/10.1111 j.1460-9568.2004.03367.x

Balconi, M., Fronda, G., \& Crivelli, D. (2018). Effects of technology-mediated mindfulness practice on stress: Psychophysiological and self-report measures. Stress, 22(2), 200-209. https://doi.org/10.1080/10253890.2018.1531845

Balconi, M., Fronda, G., Venturella, I., \& Crivelli, D. (2017). Conscious, pre-conscious and unconscious mechanisms in emotional behaviour. Some applications to the mindfulness approach with wearable devices. Applied Sciences, 7(12), 1280. https://doi.org/10.3390/app7121280

Balconi, M., Pala, F., Crivelli, D., \& Milone, V. (2019). From investigation to intervention. Biofeedback and neurofeedback biomarkers in sport. In R. Carlstedt \& M. Balconi (Eds.), Handbook of Sport Neuroscience and Psychophysiology (pp. 151-168). New York, NY: Routledge.
Bell, M., Bryson, G., Greig, T., Corcoran, C., \& Wexler, B. E. (2001). Neurocognitive enhancement therapy with work therapy: Effects on neuropsychological test performance. Archives of General Psychiatry, 58(8), 763-768. https://doi.org/10.1001/archpsyc.58.8.763

Bell, S., Partridge, B., Lucke, J., \& Hall, W. (2013). Australian university students' attitudes towards the acceptability and regulation of pharmaceuticals to improve academic performance. Neuroethics, 6(1), 197-205. https://doi.org /10.1007/s12152-012-9153-9

Borducchi, D. M. M., Gomes, J. S., Akiba, H., Cordeiro, Q., Borducchi, J. H. M., Valentin, L. S. S., ... Dias, Á. M. (2016) Transcranial direct current stimulation effects on athletes' cognitive performance: An exploratory proof of concept trial. Frontiers in Psychiatry, 7, 183. https://doi.org/10.3389 /fpsyt.2016.00183

Bostrom, N., \& Roache, R. (2011). Smart policy: Cognitive enhancement and the public interest. In J. Savulescu, R. ter Muelen, \& G. Kahane (Eds.), Enhancing Human Capacities (pp. 138-152). Oxford, UK: Wiley-Blackwell.

Bostrom, N., \& Sandberg, A. (2009). Cognitive enhancement: Methods, ethics, regulatory challenges. Science and Engineering Ethics, 15(3), 311-341. https://doi.org/10.1007 /s11948-009-9142-5

Butcher, J. (2003). Cognitive enhancement raises ethical concerns. The Lancet, 362(9378), 132-133. https://doi.org $/ 10.1016 / \mathrm{s} 0140-6736(03) 13897-4$

Chapman, S. B., Aslan, S., Spence, J. S., DeFina, L. F., Keebler, M. W., Didehbani, N., \& Lu, H. (2013). Shorter term aerobic exercise improves brain, cognition, and cardiovascular fitness in aging. Frontiers in Aging Neuroscience, 5, 75 https://doi.org/10.3389/fnagi.2013.00075

Chatterjee, A. (2004). Prospects for a cognitive neuroscience of visual aesthetics. Bulletin of Psychology and the Arts, 4(2), 55-60. https://doi.org/10.1037/e514602010-003

Cohen Kadosh, K., Johnson, M. H., Dick, F., Cohen Kadosh, R., \& Blakemore, S. J. (2013). Effects of age, task performance, and structural brain development on face processing Cerebral Cortex, 23(7), 1630-1642. https://doi.org/10.1093 /cercor/bhs 150

Colzato, L. S., Nitsche, M. A., \& Kibele, A. (2017). Noninvasive Brain Stimulation and Neural Entrainment Enhance Athletic Performance-a Review. Journal of Cognitive Enhancement, 1(1), 73-79. https://doi.org/10.1007/s41465-016-0003-2

Crews, D. J., \& Landers, D. M. (1993). Electroencephalographic measures of attentional patterns prior to the golf putt. Medicine and Science in Sports and Exercise, 25(1), 116126. https://doi.org/10.1249/00005768-199301000-00016

Crivelli, D., Fronda, G., Venturella, I., \& Balconi, M. (2019). Supporting mindfulness practices with brain-sensing devices. Cognitive and electrophysiological evidences. Mindfulness, 10(2), 301-311. https://doi.org/10.1007/s12671-018-0975-3

Curry, L. A., \& Wagman, D. F. (2011). Qualitative description of the prevalence and use of anabolic androgenic steroids by united states powerlifters. Perceptual and Motor Skills, 88(1), 224-233. https://doi.org/10.2466/pms.1999.88.1.224

Dahlin, E., Nyberg, L., Bäckman, L., \& Neely, A. S. (2008). Plasticity of executive functioning in young and older adults: Immediate training gains, transfer, and long-term maintenance. Psychology and Aging, 23(4), 720-730. https://doi.org/10.1037/a0014296

Davis, N. J. (2013). Neurodoping: Brain stimulation as a performance-enhancing measure. Sports Medicine, 43(8), 649-653. https://doi.org/10.1007/s40279-013-0027-z

Dodge, T., Williams, K. J., Marzell, M., \& Turrisi, R. (2012). Judging cheaters: Is substance misuse viewed similarly in the athletic and academic domains? Psychology of Addictive Behaviors, 26(3), 678-682. https://doi.org/10.1037/a0027872

Engvig, A., Fjell, A. M., Westlye, L. T., Skaane, N. V., Sundseth, Ø., \& Walhovd, K. B. (2012). Hippocampal subfield volumes 
correlate with memory training benefit in subjective memory impairment. Neurolmage, 61(1), 188-194. https://doi.org /10.1016/j.neuroimage.2012.02.072

Enriquez-Geppert, S., Huster, R. J., \& Herrmann, C. S. (2013). Boosting brain functions: Improving executive functions with behavioral training, neurostimulation, and neurofeedback. International Journal of Psychophysiology, 88(1), 1-16. https://doi.org/10.1016/j.ijpsycho.2013.02.001

Farah, M. J. (2005). Neuroethics: The practical and the philosophical. Trends in Cognitive Sciences, 9(1), 34-40. https://doi.org/10.1016/j.tics.2004.12.001

Farah, M. J., Illes, J., Cook-Deegan, R., Gardner, H., Kandel, E., King, P., ... Wolpe, P. R. (2004). Neurocognitive enhancement: What can we do and what should we do? Nature Reviews Neuroscience, 5(5), 421. https://doi.org $/ 10.1038 /$ nrn1390

Flöel, A., Meinzer, M., Kirstein, R., Nijhof, S., Deppe, M., Knecht, S., \& Breitenstein, C. (2011). Short-term anomia training and electrical brain stimulation. Stroke, 42(7), 2065-2067. https://doi.org/10.1161/STROKEAHA.110.609032

Fronda, G., Balconi, M., \& Crivelli, D. (2018). Neuroethical implications of neurocognitive enhancement in managerial professional contexts. Journal of Cognitive Enhancement, 2(4), 356-363. https://doi.org/10.1007/s41465-018-0100-5

Fuchs, T. (2006). Ethical issues in neuroscience. Current Opinion in Psychiatry, 2(4), 356-363. https://doi.org/10.1097 /01.yco.0000245752.75879.26

Grosprêtre, S., Ruffino, C., \& Lebon, F. (2016). Motor imagery and cortico-spinal excitability: A review. European Journal of Sport Science, 16(3), 317-324. https://doi.org/10.1080 $/ 17461391.2015 .1024756$

Hammond, D. C. (2007). Neurofeedback for the enhancement of athletic performance and physical balance. The Journal of the American Board of Sport Psychology, 1(1), 1-9.

Harvey, J. C. (2008). Enhancing evolution: The ethical case for making better people. JAMA, 299(11), 1369-1370. https://doi.org/10.1001/jama.299.11.1369

Haufler, A. J., Spalding, T. W., Santa Maria, D. L., \& Hatfield, B. D. (2000). Neuro-cognitive activity during a self-paced visuospatial task: Comparative EEG profiles in marksmen and novice shooters. Biological Psychology, 53(2-3), 131-160. https://doi.org/10.1016/S0301-0511(00)00047-8

Hung, T. M., \& Cheng, M.-Y. (2018). Neurofeedback in sport: Theory, methods, research, and efficacy. In R. Carlstedt \& M. Balconi (Eds.), Handbook of Sport Neuroscience and Psychophysiology (pp. 304-319). New York, NY: Routledge. https://doi.org/10.3389/978-2-88919-722-4

Kayser, B., \& Broers, B. (2013). Anti-doping policies: Choosing between imperfections. In Weisstub, D. (Ed.), Athletic Enhancement, Human Nature and Ethics (pp. 271-289). Dordrecht, Netherlands: Springer.

Koberda, J. L., Moses, A., Koberda, L., \& Koberda, P. (2012). Cognitive enhancement using 19-electrode $z$-score neurofeedback. Journal of Neurotherapy, 16(3), 224-230. https://doi.org/10.1080/10874208.2012.705769

Jaeggi, S. M., Buschkuehl, M., Jonides, J., \& Perrig, W. J. (2008). Improving fluid intelligence with training on working memory. Proceedings of the National Academy of Sciences, 105(19), 6829-6833. https://doi.org/10.1073/pnas.0801268105

Juengst, E. T. (1998). Group identity and human diversity: Keeping biology straight from culture. The American Journal of Human Genetics, 63(3), 673-677. https://doi.org/10.1086 /302032

Landers, D. M., Petruzzello, S. J., Salazar, W., Crews, D. J., Kubitz, K. A., Gannon, T. L., \& Han, M. (1991). The influence of electrocortical biofeedback on performance in pre-elite archers. Medicine and Science in Sports and Exercise, 23(1), 123-129. https://doi.org/10.1249/00005768-19910100000018
Lewthwaite, R., \& Wulf, G. (2017). Optimizing motivation and attention for motor performance and learning. Current Opinion in Psychology, 16, 38-42. https://doi.org/10.1016 /j.copsyc.2017.04.005

Lövdén, M., Bäckman, L., Lindenberger, U., Schaefer, S., \& Schmiedek, F. (2010). A theoretical framework for the study of adult cognitive plasticity. Psychological Bulletin, 136(4), 659-676. https://doi.org/10.1037/a0020080

Lucke, J., \& Partridge, B. (2013). Towards a smart population: A public health framework for cognitive enhancement. Neuroethics, 6(2), 419-427. https://doi.org/10.1007/s12152012-9167-3

Mirifar, A., Beckmann, J., \& Ehrlenspiel, F. (2017). Neurofeedback as supplementary training for optimizing athletes' performance: A systematic review with implications for future research. Neuroscience and Biobehavioral Reviews, 75, 419-432. https://doi.org/10.1016 /j.neubiorev.2017.02.005

Morente-Sánchez, J., \& Zabala, M. (2013). Doping in sport: A review of elite athletes' attitudes, beliefs, and knowledge. Sports Medicine, 43(6), 395-411. https://doi.org/10.1007 /s40279-013-0037-x

Nagel, S. K. (2010). Too much of a good thing? Enhancement and the burden of self-determination. Neuroethics, 3(2), 109119. https://doi.org/10.1007/s12152-010-9072-6

Nagel, S. K. (2014). Enhancement for well-being is still ethically challenging. Frontiers in Systems Neuroscience, 8, 72. https://doi.org/10.3389/fnsys.2014.00072

Nagel, S. K. (2015). When aid is a good thing: Trusting relationships as autonomy support in health care settings. The American Journal of Bioethics, 15(10), 49-51. https://doi.org/10.1080/15265161.2015.1074316

Nyberg, L., Sandblom, J., Jones, S., Neely, A. S., Petersson, K. M., Ingvar, M., \& Bäckman, L. (2003). Neural correlates of training-related memory improvement in adulthood and aging. Proceedings of the National Academy of Sciences, 100(23), 13728-13733. https://doi.org/10.1073/pnas.1735487100

Okano, H., Nakamura, M., Yoshida, K., Okada, Y., Tsuji, O., Nori, S., ... Miura, K. (2013). Steps toward safe cell therapy using induced pluripotent stem cells. Circulation Research, 112(3), 523-533. https://doi.org/10.1161/CIRCRESAHA.111.256149

Petróczi, A. (2013). The doping mindset-Part I: Implications of the functional use theory on mental representations of doping. Performance Enhancement and Health, 2(4), 153-163. https://doi.org/10.1016/j.peh.2014.06.001

Ray, K. S. (2016). Not just "study drugs" for the rich: Stimulants as moral tools for creating opportunities for socially disadvantaged students. The American Journal of Bioethics, 16(6), 29-38. https://doi.org/10.1080 /15265161.2016.1170231

Reis, J., Schambra, H. M., Cohen, L. G., Buch, E. R., Fritsch, B., Zarahn, E., ... Krakauer, J. W. (2009). Noninvasive cortical stimulation enhances motor skill acquisition over multiple days through an effect on consolidation. Proceedings of the National Academy of Sciences, 106(5), 1590-1595. https://doi.org/10.1073/pnas.0805413106

Repantis, D., Schlattmann, P., Laisney, O., \& Heuser, I. (2010). Modafinil and methylphenidate for neuroenhancement in healthy individuals: A systematic review. Pharmacological Research, 62(3), 187-206. https://doi.org/10.1016 /j.phrs.2010.04.002

Sahakian, B. J., \& Morein-Zamir, S. (2011). Neuroethical issues in cognitive enhancement. Journal of Psychopharmacology, 25(2), 197-204. https://doi.org/10.1177/0269881109106926

Salazar, W., Landers, D. M., Petruzzello, S. J., Han, M., Crews, D. J., \& Kubitz, K. A. (1990). Hemispheric asymmetry, cardiac response, and performance in elite archers. Research Quarterly for Exercise and Sport, 61(4), 351-359. https://doi.org/10.1080/02701367.1990.10607499 
Sandel, M. J. (2004, April). The case against perfection: What's wrong with designer children, bionic athletes, and genetic engineering (Electronic version). The Atlantic Monthly. Retrieved from http://www.theatlantic.com/doc/prem /200404/sandel.

Schelle, K. J., Faulmüller, N., Caviola, L., \& Hewstone, M. (2014). Attitudes toward pharmacological cognitive enhancement-a review. Frontiers in Systems Neuroscience, 8, 53. https://doi.org/10.3389/fnsys.2014.00053

Schooler, C. (1984). Psychological effects of complex environments during the life span: A review and theory. Intelligence, 8(4), 259-281. https://doi.org/10.1016/01602896(84)90011-4

Schooler, C., Mulatu, M. S., \& Oates, G. (1999). The continuing effects of substantively complex work on the intellectual functioning of older workers. Psychology and Aging, 14(3), 483-506. https://doi.org/10.1037/0882-7974.14.3.483

Shook, J. R., \& Giordano, J. (2016). Defining contexts of neurocognitive (performance) enhancements: Neuroethical considerations and implications for policy. Cognitive Enhancement: Ethical and Policy Implications in International Perspectives, 76 . https://doi.org/10.1093/acprof:oso /9780199396818.003.0006

Singh, I., \& Kelleher, K. J. (2010). Neuroenhancement in young people: Proposal for research, policy, and clinical management. AJOB Neuroscience, 1(1), 3-16. https://doi.org/10.1080/21507740903508591

Svetlov, S. I., Kobeissy, F. H., \& Gold, M. S. (2007). Performance enhancing, non-prescription use of Ritalin performance: A comparison with amphetamines and cocaine. Journal of Addictive Diseases, 26(4), 1-6. https://doi.org/10.1300/J069v26n04_01

Valenzuela-Fernández, A., Cabrero, J. R., Serrador, J. M., \& Sánchez-Madrid, F. (2008). HDAC6: A key regulator of cytoskeleton, cell migration and cell-cell interactions. Trends in Cell Biology, 18(6), 291-297. https://doi.org/10.1016 /j.tcb.2008.04.003

Vargo, E. J., James, R. A., Agyeman, K., MacPhee, T., McIntyre, R., Ronca, F., \& Petróczi, A. (2014). Perceptions of assisted cognitive and sport performance enhancement among university students in England. Performance Enhancement and Health, 3(2), 66-77. https://doi.org/10.1016 /j.peh.2015.02.001
Verhaeghen, P., Marcoen, A., \& Goossens, L. (1992). Improving memory performance in the aged through mnemonic training: A meta-analytic study. Psychology and Aging, 7(2), 242-251. https://doi.org/10.1037/0882-7974.7.2.242

Vernon, D. J. (2005). Can neurofeedback training enhance performance? An evaluation of the evidence with implications for future research. Applied Psychophysiology Biofeedback, 30(4), 347. https://doi.org/10.1007/s10484-005-8421-4

Vitor-Costa, M., Okuno, N. M., Bortolotti, H., Bertollo, M., Boggio, P. S., Fregni, F., \& Altimari, L. R. (2015). Improving cycling performance: Transcranial direct current stimulation increases time to exhaustion in cycling. PLoS ONE, 10(12), e0144916. https://doi.org/10.1371/journal.pone.0144916

Williams, P. S., Hoffman, R. L., \& Clark, B. C. (2013). Preliminary evidence that anodal transcranial direct current stimulation enhances time to task failure of a sustained submaximal contraction. PLOS ONE, 8(12), e81418. https://doi.org /10.1371/journal.pone.0081418

Wolpe, P. R. (2002). Treatment, enhancement, and the ethics of neurotherapeutics. Brain and Cognition, 50(3), 387-395. https://doi.org/10.1016/S0278-2626(02)00534-1

Wood, T. (2006). Brain and body in sport and exercise. British Journal of Sports Medicine, 40, 880-881. https://doi.org /10.1136/bjsm.2006.026872

Zelinski, E. M., \& Reyes, R. (2010). Cognitive benefits of computer games for older adults. Gerontechnology, 8(4), 220-235. https://doi.org/10.4017/gt.2009.08.04.004.00

Zhu, F. F., Yeung, A. Y., Poolton, J. M., Lee, T. M. C., Leung, G. K. K., \& Masters, R. S. W. (2015). Cathodal transcranial direct current stimulation over left dorsolateral prefrontal cortex area promotes implicit motor learning in a golf putting task. Brain Stimulation, 8(4), 784-786. https://doi.org/10.1016 /j.brs.2015.02.005

Zoefel, B., Huster, R. J., \& Herrmann, C. S. (2011). Neurofeedback training of the upper alpha frequency band in EEG improves cognitive performance. Neurolmage, 54(2), 1427-1431. https://doi.org/10.1016/j.neuroimage.2010.08.078

Received: June 11, 2019

Accepted: July 31, 2019

Published: September 13, 2019 